\title{
SUBJECTIVE WELL-BEING AND JOB TYPES: NEW EVIDENCE FROM CHINA
}

\author{
Meng Yan', Kai Shi ${ }^{2}$ \\ ${ }^{1}$ University of New Hampshire, Durham, USA, my1019@wildcats.unh.edu \\ ${ }^{2}$ Northeast Normal University, Changchun, China, shik142@nenu.edu.cn
}

\begin{abstract}
Research purpose. The job types might be potential determinants of subjective well-being (SWB), which is seldom investigated in the current literature. This article examines this relationship by collecting data from the Chinese Household Income Project in 2013 to explore this relationship.
\end{abstract}

Approach. In line with existing studies on SWB, we apply the ordered probit model and further estimate the effects of different job types on SWB.

Findings. This article demonstrates that individuals employed by Sino-foreign joint enterprises tend to have the lowest SWB. On the contrary, those employed by the public sector and private enterprises are more likely to acquire higher satisfaction.

Practical implications. To conclude, job types are closely linked with SWB and job types should be incorporated as a crucial factor when further analysing the SWB.

Keywords: Subjective well-being; Job types; Chinese household income project; Ordered Probit Model.

JEL codes: I31; J28.

\section{Introduction}

Subjective well-being (hereafter SWB) refers to self-reported happiness, which is consistent with the concept of utility in economics. In modern economic theory, utility plays a pivotal role in our research. For example, a representative agent always faces maximising his or her utility function under resource restrictions. SWB initially stems from the psychological area, and economists use this indicator as a measurement of individual satisfaction. By measuring the magnitude of SWB and identifying the factors that influence SWB, policymakers can clearly understand the effect of a specified economic policy on social welfare.

Which factor influences SWB? This question has been widely debated by economists, and the existing literature mainly focuses on two factors that affect SWB. The first factor is income or relative income. Headey and Wooden (2004) pointed out that household income had significant but little effect on SWB by using HILDA (The Household, Income and Labour Dynamics in Australia) survey data from Australia. Guven and Sørensen (2012) used the U.S. General Social Survey from 1972 to 2004 and concluded that high income was correlated with the higher level of SWB; however, high reference group income was negatively related to SWB. Goerke and Pannenberg (2015) used the German SocioEconomic Panel (SOEP) data to explore the evidence between income comparisons and SWB. They concluded that there were negative correlations between comparison intensity and SWB for colleagues or people in the same occupation and friends. Antinyan (2016) also studied the relationship between SWB and reference group income by using data from three republics of the South Caucasus. The conclusion verified that SWB went down when reference group members were richer than they were and SWB was enhanced when reference group members were poorer.

The second factor to explain SWB is consumption. Ahuvia (2002) studied the impact of different attitudes toward consumption at the micro- and macrolevel on SWB. Luttmer (2005) concluded that high levels of SWB come from their consumption under the framework of the utility function. Hudders and Pandelaere (2012) measured the impact of luxury consumption on SWB by comparing materialistic and less materialistic consumers. Iyer and Muncy (2009) further studied the effect of attitude toward 
consumption on SWB and indicated that micro attitude was always positively related to a consumer's SWB and macro attitude was always negatively related to SWB.

Although income and consumption are two important determinants of SWB, the bulk of literature also study other factors that may influence SWB. In a recent article, Fujiwara and Lawton (2016) pointed out there were not any empirical research to discuss the relationship between employment in creative occupations and SBW directly. They used the UK's Annual Population Survey to empirically analyse whether creative occupations are associated with a higher level of SWB and concluded that creative occupations will result in higher SWB than ordinary occupations. Indeed, existing literature seldom explores the relationship between SWB and different job types, although some research may incorporate job variables in their regression models. So, the relationship between job types and SWB should be emphasised, and job types perhaps are important potential factors to interpret SWB.

The marginal contributions in this article are twofold. First, the data on SWB are difficult to collect in emerging countries because of the costly survey plan. Therefore, this article enriches the literature on determinants of SWB in developing countries. Second, this article complements to some study (e.g. Fujiwara \& Lawton, 2016) by analysing the potential relationship between occupation and SWB through a detailed separation of job types.

The SWB collected from questionnaires is a discrete and ordered variable, therefore, traditional panel data regression and cross-section regression (e.g. Cai \& Park, 2016; Goerke \& Pannenberg, 2015) are inappropriate in investigating the marginal effects of different job types on SWB because the marginal effects are not constant because of discrete dependent variable. Therefore, current studies (such as Eggers et al., 2006; Ye \& Lin, 2015) turn to rest on the ordered probit model. In a similar manner, we also adopt the ordered probit model to assess the marginal effects of different job types on SWB. Our article indicates that individuals employed by Sino-foreign joint enterprises tend to have the lowest SWB. On the contrary, those employed by the public sector and private enterprises are more likely to acquire higher satisfaction.

The remainder of this article is organised as follows. Section 2 discusses data source and variables choice, especially distinct conceptions to define dependent variables - SWB. Section 3 presents the regression model and analyses empirical results. Section 4 concludes.

\section{Data and Variables}

There are two core variables in our article: job types and SWB, from the questionnaire used by the Chinese Household Income Project (CHIP) in 2013, which is the latest survey conducted by the CHIP. According to the National Bureau of Statistics in China, the structure of employment keeps constant since 2012. Therefore, to some extent, we can use the data surveyed by the CHIP in 2013 to characterise the relationship between SWB and job types in the recent years.

Then we identify that SWB has five different levels and define the numerical values of SWB as follows: very happy $=5$, happy $=4$, so-so $=3$, not very happy $=2$ and not happy at all $=1$. According to the survey questionnaire, the employment types of jobs can be divided into eight categories, which are government and party agencies $=1$, public institution $=2$, solely state-owned/state-holding enterprises $=3$, collective enterprises $=4$, Sino-foreign joint venture/solely foreign-owned enterprises $=5$, individual enterprises $=6$, private enterprises $=7$ and others. Other job types will be regarded as the baseline group; as a result, when we estimate the ordered probit model, we will drop this job type and only focus on other seven job types.

According to Fujiwara and Campbell (2011), the control variables incorporate age (age in years), gender (a dummy variable, 1 if male, 0 if female), marital status (dummy variable, 1 if married, 0 if other marital status), ethnicity (dummy variable, 1 if Han nationality, 0 if others), disability ( 1 if disabled, 0 if others), years of education (the corresponding years according to the level of education completed) and income (total income in 2013).

Before estimating our regression model, we should have a detailed discussion on the choice of subject well-being by comparing with the existing literature. Fujiwara and Lawton (2016) made an extension of the concept of SWB; they not only considered the traditional concept of SWB, for example, life 
satisfaction and happiness, but also measured the value of worthwhileness and anxiety. Besides, they defined the scale of these indicators from 0 to 10 , where 0 represents nothing was felt. Cai and Park (2016) used global life satisfaction as a possible measure of SWB, which is defined as the expected lifetime utility (the sum of current and future discounted utility). They also pointed out five possible values to represent SWB, in which 1 denotes very dissatisfied, 2 denotes dissatisfied, 3 denotes just soso, 4 denotes satisfied and 5 denotes very satisfied. So, the value range of SWB adopted by Cai and Park (2016) is very similar to the data on SWB used in this article. As we mentioned before, an individual is hard to define his/her happiness between 4 and 5 when the value ranges from 1 to 10 but is easier to define his/her happiness between happy and just so-so when the value ranges from 1 to 5 . So, it is reasonable to use the survey result of SWB based on 5 categories rather than based on 10 categories, although 10 categories may provide more variation of the dependent variable.

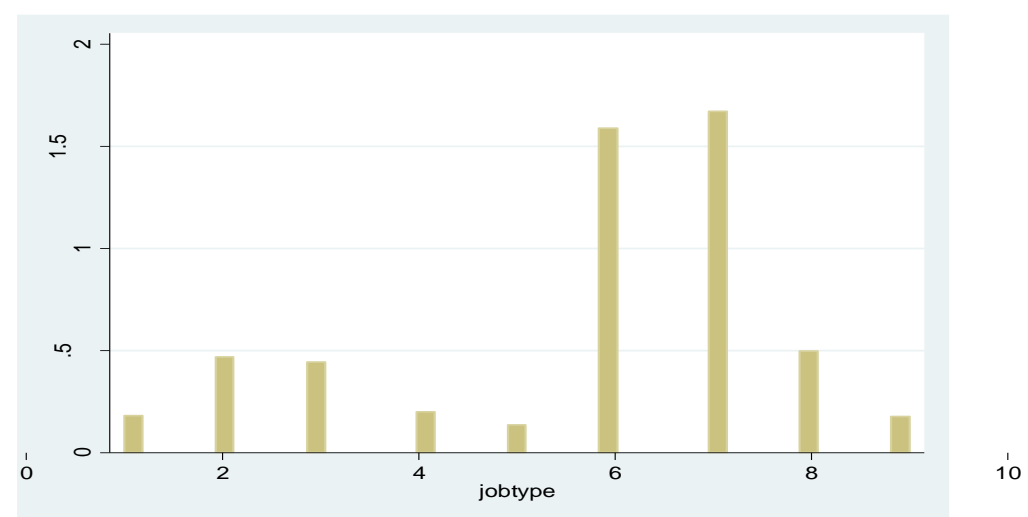

Fig. 1. Histogram of Job Types (Source: Author's Calculation)

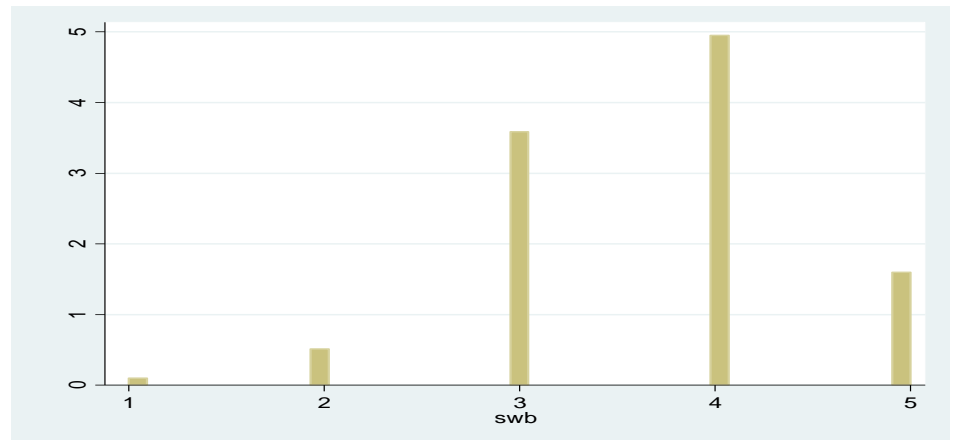

Fig. 2. Histogram of SWB (Source: Author's Calculation)

Figures 1 and 2 present the distributions of SWB and job types. From these two figures, we can find out that the value range of SWB for most observations is between 3 and 4, that is, from so-so to happy; in the meanwhile, the occupations dominated the highest percentage in our sample are individual enterprises (=6) and private enterprises (=7). Actually, with the transition from the planned economy system to market economy system in China, there is a significant decline in the number of labours employed by the state-owned enterprise when compared with the past decades.

Table 1 reports the descriptive statistics of SWB and controlling variables used in our regression model. After deleting missing values, the number of total observations in our sample is 22,967 (following the data instruction from the CHIP, they have already removed the unreliable observation). The percentage of residents employed by individual enterprises and private enterprises are $29.6 \%$ and $31.1 \%$, respectively; in other words, more than $60 \%$ labours work in private sector in our sample, which is consistent with Chinese market economy reform since 1978. Table 1 further indicates the percentages of employees in government and party agencies and Sino-foreign joint venture/solely foreign-owned enterprises are relatively low. 
Table 1. Descriptive Statistics (Source: Author's calculation)

\begin{tabular}{cccc}
\hline \hline Variables & Description & Mean & S.D. \\
\hline SWB & Subjective well-being & 3.780 & 0.813 \\
AGE & Age of residents & 40.592 & 11.806 \\
MALE & $=1$ if male & 0.608 & 0.488 \\
MARITAL & $=1$ if married & 0.825 & 0.380 \\
ETHNICITY & $=1$ if HAN nationality & 0.960 & 0.197 \\
DISABILITY & $=1$ if disabled & 0.021 & 0.142 \\
EDUC & Years of education & 9.887 & 3.385 \\
INCOME & Income in 2013 (10,000 Yuan) & 6.063 & 5.437 \\
GOV & Government and party agencies & 0.034 & 0.181 \\
PUBLIC & Public institution & 0.087 & 0.283 \\
SENTER & Solely state-owned/state-holding enterprises & 0.083 & 0.275 \\
CENTER & Collective enterprises & 0.038 & 0.190 \\
SFENTER & Sino-foreign joint/solely foreign-owned enterprises & 0.025 & 0.158 \\
IENTER & Individual enterprises & 0.296 & 0.456 \\
PENTER & Private enterprises & 0.311 & 0.463 \\
\hline
\end{tabular}

Note: The sample size of data is 22,967. S.D. is standard deviation.

\section{Empirical Results}

In line with previous studies (Litchfield et al., 2012; Ye \& Lin, 2015) on SWB, the ordered probit model is specified as follows:

$$
S W B_{i}=X^{\prime} \beta+Z^{\prime} \delta+\varepsilon_{i}
$$

where $X$ represents seven different job types described in the preceding section and $Z$ represents controlling variables, which include age, gender, marital status, ethnicity, disability, years of education and income. We assume $\varepsilon_{i}$ is a standard normally distributed error term and the accumulative function of $\varepsilon_{i}$ is denoted as $\mathrm{F}(\cdot)$. If $S W B_{i}^{*}$ is latent or unobservable variable, then observed $S W B_{i}$ is determined from $S W B_{i}^{*}$ using the following rule:

$$
S W B_{i}=\left\{\begin{array}{llr}
1 & \text { if } & S W B_{i}^{*} \leq \gamma_{1} \\
2 & \text { if } & \gamma_{1}<S W B_{i}^{*} \leq \gamma_{2} \\
3 & \text { if } & \gamma_{2}<S W B_{i}^{*} \leq \gamma_{3} \\
4 & \text { if } & \gamma_{3}<S W B_{i}^{*} \leq \gamma_{4} \\
5 & \text { if } & \gamma_{4}<S W B_{i}^{*} \leq \gamma_{5}
\end{array}\right.
$$

where values 1, 2, 3, 4 and 5 are threshold values, denoted as $S W B_{i}=j$ when $\gamma_{j-1}<S W B_{i}^{*} \leq \gamma_{j}$. The cutting points $\gamma$ are estimated along with model coefficients through maximum likelihood estimation (MLE). The maximise log likelihood function is listed as follows:

$$
\log L(\beta, \gamma)=\sum_{i=1}^{N} \sum_{j=1}^{5} \log \left(P\left(S W B_{i}=\mathrm{j} \mid X_{i}, Z_{i}, \beta, \delta, \gamma\right)\right) \cdot I\left(S W B_{i}=\mathrm{j}\right)
$$

where $P\left(S W B_{i}=\mathrm{j} \mid X_{i}, Z_{i}, \beta, \delta, \gamma\right)$ represents the probabilities of observing each value of SWB and I (.) is an indicator function that takes the value 1 if $\mathrm{I}\left(S W B_{i}=\mathrm{j}\right)$ is true and 0 if the $\mathrm{I}\left(S W B_{i}=\mathrm{j}\right)$ is false. In the ordered probit model, the marginal effects will give the effect of a change in one of the variables on the probability of each ordered category appearing dependent on given values of covariates as indicated by their parameter estimates. The marginal effect is expressed as 


$$
M E=\frac{\partial \operatorname{Pr}(S W B=j)}{\partial x}=\left[F^{\prime}\left(\gamma_{j-1}-X^{\prime} \beta-Z^{\prime} \delta\right)-F^{\prime}\left(\gamma_{j}-X^{\prime} \beta-Z^{\prime} \delta\right)\right] \beta
$$

Table 2 reports the estimated coefficients by ordered probit model and Ordinary Least Squares (OLS) model. Table 3 further reports the marginal effects, which represent the probability of changes in the dependent variables when explanatory variables change.

We initially focus on the sign and magnitude of estimated coefficients from Table 2 and then analyse marginal effects in Table 3. In Table 2, except the coefficient of SFENTER (-0.010), all the other estimated coefficients of different job types are positive, in which the coefficients of GOV, PUBLIC and SENTER are much larger than other job types. This means individuals employed by Sino-foreign joint venture/solely foreign-owned enterprises tend to have the lowest SWB; on the contrary, those employed by the government, public institute, and state-holding enterprises are more likely to acquire higher satisfaction. Working in Sino-foreign joint venture/solely foreign-owned enterprises will bear more pressure than working in other sectors because employees working in such area not only face higher entrance criterion (such as master multiple languages, higher education degree) but also face stricter performance pressure and a relatively lower sense of belonging. Even though employees make more money in Sino-foreign joint venture/solely foreign-owned enterprises, this may not compensate for their payouts and result in lower SWB.

Table 2. Regression Results: Subjective Well-being and Jobs Types (Source: Author's Calculation)

\begin{tabular}{|c|c|c|c|c|}
\hline \multirow{2}{*}{$\begin{array}{c}\text { Independent } \\
\text { Variables }\end{array}$} & \multicolumn{2}{|c|}{ Ordered Probit } & \multicolumn{2}{|c|}{ OLS } \\
\hline & Coefficient & p-Value & Coefficient & p-Value \\
\hline Age & $0.002 * *$ & 0.038 & $0.001 * *$ & 0.03 \\
\hline Male & $-0.026 *$ & 0.073 & $-0.019 *$ & 0.08 \\
\hline Marital & $0.051 * *$ & 0.016 & $0.038 * *$ & 0.02 \\
\hline Ethnicity & $0.158 * * *$ & 0.000 & $0.118 * * *$ & 0.00 \\
\hline Disability & 0.055 & 0.270 & 0.044 & 0.24 \\
\hline Educ & $0.011 * * *$ & 0.000 & $0.008 * * *$ & 0.00 \\
\hline Income & $0.003 * *$ & 0.042 & $0.002 *$ & 0.06 \\
\hline Gov & $0.094 * *$ & 0.036 & $0.066 * *$ & 0.05 \\
\hline Public & $0.068 * *$ & 0.041 & $0.504 * *$ & 0.04 \\
\hline Senter & $0.087 * * *$ & 0.008 & $0.062 *$ & 0.01 \\
\hline Center & 0.068 & 0.107 & $0.056^{*}$ & 0.08 \\
\hline Sfenter & -0.010 & 0.832 & -0.007 & 0.86 \\
\hline Ienter & 0.032 & 0.181 & 0.023 & 0.19 \\
\hline Penter & $0.040 *$ & 0.092 & $0.030 *$ & 0.10 \\
\hline Likelihood ratio & $90.86 * * *$ & 0.00 & & \\
\hline Log likelihood & \multicolumn{2}{|c|}{$-27,404.67$} & & \\
\hline
\end{tabular}

Given the Chinese unique economic structure, we regard the government institutes, public institutes and state-owned enterprises as the public sector. Hence, individuals employed by the public sector will gain more satisfaction. The possible reasons can be further interpreted from two perspectives. First, the working pressure in the public sector is relatively smaller than that in other enterprises, namely, employees will not have performance requirements. Besides, they do not need to worry about unemployment once they find a job in public sector in China; in the meanwhile, they can enjoy the best social security and implicit subsidy provided by the government. This is the main reason to explain why employed by the public sector will have higher SWB. Second, as we mentioned before, working in the public industry means higher political status, which accords with the traditional official rank standard of China. Therefore, a job type with higher social status might be more attractive than the job with a higher wage. In particular, the conclusion obtained here is also consistent with that of Goerke and Pannenberg (2015); their empirical results also showed that employed by the public sector is possible to have higher happiness, although they used the dataset from Germany. 
Another conclusion from Table 2 is that the estimated coefficient of PENTER is also positive and statistically significant, which suggests individuals employed by private enterprises also exhibit higher SWB. Since the mid-1990s, the Chinese government began to reform the development pattern of industries, primarily through complex forces of restriction, competition and privatisation to reshape Chinese industry (Naughton, 2007). Besides, the Chinese government also started to provide further legitimacy and legal protection to the private enterprise from the late 1990s. With the establishment of clarifying property right, the profits of private enterprise gradually increased, and the income level of workers employed by private enterprise also begin to rise. In the recent years, the percentage of private enterprise accounting for GDP (gross domestic product) in China has been more than 60\%; therefore, the employees in private enterprises will get better treatment, such as salary and working environment; this may illustrate why the individuals who work in private enterprise will have positive estimated coefficients in SWB regression equation.

Table 3. Marginal Effects of Ordered Probit Model (Source: Author's calculation)

\begin{tabular}{|c|c|c|c|c|c|}
\hline Variables & $\begin{array}{c}\text { Very happy } \\
\text { SWB = 5 }\end{array}$ & $\begin{array}{c}\text { Happy } \\
\text { SWB = } 4\end{array}$ & $\begin{array}{c}\text { So-so } \\
\text { SWB = } 3\end{array}$ & $\begin{array}{c}\text { Not very happy } \\
\text { SWB }=\mathbf{2}\end{array}$ & $\begin{array}{c}\text { Not happy at } \\
\text { all } \\
\text { SWB }=1 \\
\end{array}$ \\
\hline \multirow{2}{*}{ Age } & $0.0004 * *$ & $0.0002 * *$ & $-0.0004 * *$ & $-0.0001 * *$ & $-0.00004 * *$ \\
\hline & $(0.038)$ & $(0.038)$ & $(0.038)$ & $(0.038)$ & $(0.039)$ \\
\hline \multirow{2}{*}{ Male } & $-0.006 *$ & $-0.004 *$ & $0.007 *$ & $0.002 *$ & $0.001 *$ \\
\hline & $(0.074)$ & $(0.071)$ & $(0.073)$ & $(0.072)$ & $(0.073)$ \\
\hline \multirow{2}{*}{ Marital } & $0.012 * *$ & $0.008 * *$ & $-0.014 * *$ & $-0.005 * *$ & $-0.001 * *$ \\
\hline & $(0.015)$ & $(0.021)$ & $(0.016)$ & $(0.019)$ & $(0.022)$ \\
\hline \multirow{2}{*}{ Ethnicity } & $0.034 * * *$ & $\mathbf{0 . 0 2 8} * * *$ & $-0.041 * * *$ & $-0.016 * * *$ & $-0.005 * * *$ \\
\hline & $(0.000)$ & $(0.000)$ & $(0.000)$ & $(0.000)$ & $(0.000)$ \\
\hline \multirow{2}{*}{ Disability } & 0.013 & 0.008 & -0.015 & -0.005 & -0.001 \\
\hline & $(0.283)$ & $(0.237)$ & $(0.273)$ & $(0.252)$ & $(0.241)$ \\
\hline \multirow{2}{*}{ Educ } & $0.002 * * *$ & $\mathbf{0 . 0 0 2} * * *$ & $-0.003 * * *$ & $-0.001 * * *$ & $-\mathbf{0 . 0 0 0} * * *$ \\
\hline & $(0.000)$ & $(0.000)$ & $(0.000)$ & $(0.000)$ & $(0.000)$ \\
\hline \multirow{2}{*}{ Income } & $0.001 * *$ & $0.000 * *$ & $-0.001 * *$ & $-0.0002 * *$ & $-0.000 * *$ \\
\hline & $(0.042)$ & $(0.042)$ & $(0.042)$ & $(0.042)$ & $(0.044)$ \\
\hline \multirow{2}{*}{ Gov } & $0.023 * *$ & $0.013 * *$ & $-0.026 * *$ & $-0.007 * *$ & $-0.002 * *$ \\
\hline & $(0.044)$ & $(0.017)$ & $(0.037)$ & $(0.025)$ & $(0.021)$ \\
\hline \multirow{2}{*}{ Public } & $0.016 * *$ & $0.010 * *$ & $-0.018 * *$ & $-0.006 * *$ & $-0.002 * *$ \\
\hline & $(0.046)$ & $(0.028)$ & $(0.042)$ & $(0.033)$ & $(0.030)$ \\
\hline \multirow{2}{*}{ Senter } & $0.209 * *$ & $\mathbf{0 . 0 1 2} * * *$ & $-0.024 * * *$ & $-0.007 * * *$ & $-\mathbf{0 . 0 0 2} * * *$ \\
\hline & $(0.010)$ & $(0.003)$ & $(0.008)$ & $(0.005)$ & $(0.004)$ \\
\hline \multirow{2}{*}{ Center } & 0.016 & $0.010 *$ & -0.018 & $-0.006 *$ & $-0.002 *$ \\
\hline & (0.119) & $(0.080)$ & (0.109) & $(0.092)$ & $(0.084)$ \\
\hline \multirow{2}{*}{ Sfenter } & -0.002 & -0.002 & 0.003 & 0.001 & 0.000 \\
\hline & $(0.831)$ & $(0.834)$ & $(0.832)$ & $(0.833)$ & $(0.834)$ \\
\hline \multirow{2}{*}{ Ienter } & 0.007 & 0.005 & -0.009 & -0.002 & -0.001 \\
\hline & $(0.184)$ & $(0.174)$ & $(0.181)$ & $(0.177)$ & $(0.175)$ \\
\hline \multirow{2}{*}{ Penter } & $0.009 *$ & $0.006 *$ & $-0.011 *$ & $-0.004 *$ & $-0.001 *$ \\
\hline & $(0.094)$ & $(0.086)$ & $(0.092)$ & $(0.089)$ & $(0.088)$ \\
\hline
\end{tabular}

Note: The marginal effects calculated here are overall average marginal effects at every point. p-Value is presented in the parenthesis. $* * *$ denotes statistical significance at $1 \%, * *$ denotes significance at $5 \%, *$ denotes significance at the $10 \%$.

Next, we turn to interpret the estimated marginal effects in Table 3 and mainly discuss the impacts of different jobs on SWB when SWB takes the value of 5 (very happy). The estimated effects of GOV is 0.0223 , which means compared with other job types, the individuals employed by the government and party agencies increase the probability of reporting very happy by 2.3 percentage point. For individuals who work in public institution, state-owned enterprises, and private enterprises, they also increase the chances of reporting very happy compared with other job types. The exception here is SFENTER, that 
is, individuals employed by Sino-foreign joint enterprise; they decrease the likelihood of reporting very happy by 0.2 percentage point, although the estimated marginal effect here is statistically insignificant. The marginal effects further support our previous analysis, that is, for individuals who choose to work in public sector and private enterprises, they are more likely to have higher SWB, but those employed by Sino-foreign enterprise tend to report lower satisfaction.

\section{Conclusions}

Considering job types may be the potential determinants of SWB, this article examines this relationship by using data from the Chinese Household Income Project in 2013. In common with much of existing studies on SWB, this article uses the ordered probit model to estimate the effect of different job types on SWB. This article demonstrates that individuals employed by Sino-foreign joint enterprises tend to have the lowest SWB. On the contrary, those employed by the public sector and private enterprises are more likely to acquire higher satisfaction. This article concludes that job types are closely linked with SWB and job types should be incorporated as a crucial factor when further analysing the SWB.

The policy implications here are obvious. From the perspective of social equality, the government can compensate those employed by Sino-foreign joint enterprises to increase their SWB. For example, the government can implement tariff exemption or export subsidy for Sino-foreign joint enterprises to improve their profit and increase the employee's income level indirectly.

Besides, the relationship between job types and SWB in emerging countries will be more significant than in developed countries. One possible reason is, in emerging countries, the salary and working environment of most workers employed by the enterprise (private or individual) are worse than that of those working in the public sector. For future studies, we can consider the quasi-experimental analytical methods, such as difference-in-difference and regression discontinuity, to evaluate the change of policy aimed at improving workers' welfare in transition economy countries and have a better understanding of how different types of jobs can affect SWB in the long run (Fujiwara \& Lawton, 2016).

\section{Acknowledgements}

This study was funded by the Chinese Ministry of Education Humanities and Social Science Fund under Grant No. 15YJC790086.

\section{References}

Ahuvia, A. C., (2002). Individualism/collectivism and cultures of happiness: A theoretical conjecture on the relationship between consumption, culture and subjective well-being at the national level. Journal of Happiness Studies, 3(1), 23-36.

Antinyan, A. (2016). Reference group income and subjective well-being: Empirical evidence from low-income transition economies. Social Indicators Research, 127(3), 1333-1348.

Cai, S., \& Park, A. (2016). Permanent income and subjective well-being. Journal of Economic Behavior \& Organization, 130, 298-319.

Eggers, A., Gaddy, C., \& Graham, C. (2006). Well-being and unemployment in Russia in the 1990s: Can society's suffering be individuals' solace?. The Journal of Socio-Economics, 35(2), 209-242.

Fujiwara, D., \& Campbell, R. (2011). Valuation techniques for social cost-benefit analysis: stated preference, revealed preference and subjective well-being approaches: a discussion of the current issues. HM Treasury.

Fujiwara, D., \& Lawton, R. N. (2016). Happier and more satisfied? Creative occupations and subjective wellbeing in the United Kingdom. Psychosociological Issues in Human Resource Management, 4(2), 50.

Goerke, L., \& Pannenberg, M. (2015). Direct evidence for income comparisons and subjective well-being across reference groups. Economics Letters, 137, 95-101.

Guven, C., \& Sørensen, B. E. (2012). Subjective well-being: Keeping up with the perception of the Joneses. Social Indicators Research, 109(3), 439-469. 
Headey, B., \& Wooden, M. (2004). The effects of wealth and income on subjective well-being and ill-being. Economic record, 80, S24-S33.

Hudders, L., \& Pandelaere, M. (2012). The silver lining of materialism: The impact of luxury consumption on subjective well-being. Journal of Happiness Studies, 13(3): 411-437.

Iyer, R., \& Muncy, J. A. (2009). Purpose and object of anti-consumption. Journal of Business Research, 62(2), 160-168.

Litchfield, J., Reilly, B., \& Veneziani, M. (2012). An analysis of life satisfaction in Albania: A heteroscedastic ordered probit model approach. Journal of Economic Behavior \& Organization, 81(3), 731-741.

Luttmer, E. F., (2005). Neighbors as Negatives: Relative Earnings and Well-Being. The Quarterly Journal of Economics, 963-1002.

Ye, Y., \& Lin, L. (2015). Examining relations between locus of control, loneliness, subjective well-being, and preference for online social interaction. Psychological reports, 116(1), 164-175. 